\title{
THREE-DIMENSIONAL BIOMECHANICAL MODEL OF BENIGN PAROXYSMAL POSITIONAL VERTIGO IN THE SEMI-CIRCULAR CANAL
}

\author{
Nebojsa Zdravkovic, Zarko Milosevic, Igor Saveljic, Dalibor Nikolic, Vladimir Miloradovic, Nenad Filipovic
}

Original scientific paper

Benign Paroxysmal Positional Vertigo (BPPV) is one of the most common vestibular disorders occuring due to the presence of basophilic particles in the semicircular canals (SCC). Three-dimensional biomechanical model of the SCC is described with full 3D fluid-structure interaction of particles, wall, cupula deformation and endolymph fluid flow. The model of the SCC with parametric defined dimension and fully 3D three SCC from patient specific 3D reconstruction is presented. Navier-Stokes equations with continuity equations described fluid flow while Arbitrary-Lagrangian Eulerian (ALE) formulation is used for mesh motion. Fluid-structure interaction for fluid coupling with cupula deformation is used. Particle tracking algorithm has been used for particle motion. Different size and number of particles with their full interaction between themselves, wall and cupula deformation are used. Velocity distribution, shear stress and force from endolymph side are presented for parametric one SCC and patient specific three SCC. All the models are used for correlation with the same experimental protocols with head moving and nystagmus eye tracking. Full fluid-structure interaction of otoconia particles, wall, cupula deflection and endolymph flow in three-dimension give more details and understanding of the pathology of the specific patient in standard clinical diagnostic and therapy procedure for BPPV.

Keywords: biomechanical model; BPPV; fluid-structure interaction; semi-circular canals; sedimenting particle

Trodimenzijski biomehanički model benigne paroksizmalne pozicijske vrtoglavice u polukružnom kanalu

Izvorni znanstveni članak

Benigna paroksizmalna pozicijska vrtoglavica (BPPV) je najčešći poremećaj vestibularnog sustava koji uzrokuju bazofilne čestice u polukružnom kanalu. Trodimenzijski biomehanički model SCC je opisan s potpunom 3D interakcijom fluid-struktura, čestica, zidova, deformacije kupule i endolimfnog strujanja fluida. Prikazan je model SCC s parametarskim definiranim dimenzijama i trodimenzijskim 3D rekonstrukcijama određenog pacijenta. Korištene su pune Navier-Stokes jednadžbe s jednadžbama kontinuiteta opisuje tok fluida dok je Arbitrary-Lagrangian Eulerian (ALE) formulacija korištena za gibanje mreže. Korištena je interakcija fluid-struktura za spajanje tekućine s deformacijom kupule. Primijenjen je algoritam za praćenje čestica. Korištene su različite veličine i broj čestica sa svojom punom interakcijom između sebe, zida i deformacije kupule. Raspodjela brzina, smičnog naprezanja i sila od strane endolimfe je prikazana kao parametar za jedan SCC kao i za tri SCC od određenog pacijenta. Svi modeli se koriste u korelaciji s istim eksperimentalnim protokolima s pokretima glave i gibanjem očiju - nystagmus. Puna interakcija fluid-struktura, čestica otoconia, zidova, deformacije kupula i endolimfnog fluida u tri dimenzije dat će više detalja za razumijevanje patologije specifičnog pacijenta u standardnoj kliničkoj dijagnostici i proceduri terapije za BPPV.

Ključne riječi: biomehanički model; BPPV; interakcija fluid-struktura; polukružni kanal; taloženje čestica

\section{Introduction}

The causes of balance disorders can be multiple [1], in more than $50 \%$ of the cases, causes are related to pathologies of the inner ear, $15 \%$ are psychological, such as anxiety; in about $5 \%$ of cases these are mainly neurological; $5 \%$ are medical, such as high blood pressure or heart conditions like arrhythmia; while in the remaining $25 \%$ these are multifactorial. Balance problems very often lead to falls [2], which usually needs additional investigation, partly because the difficulties in determining the origin of the fall.

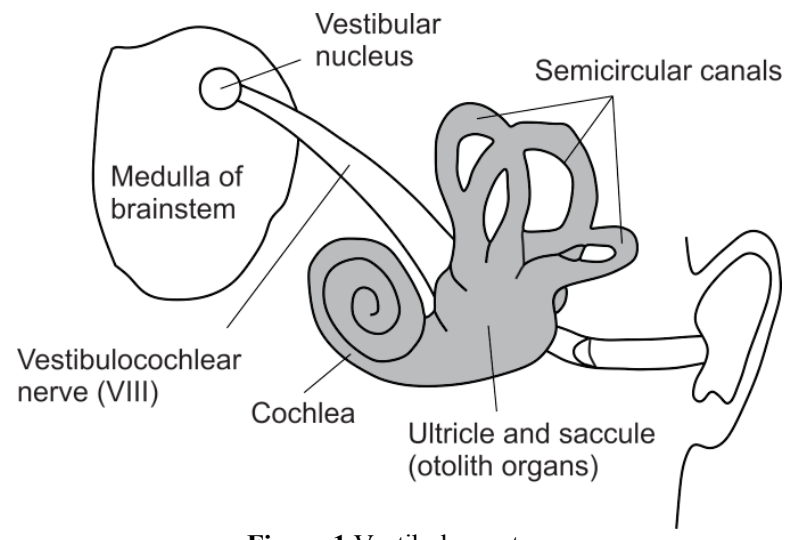

Figure 1 Vestibular system
The vestibular system elements have been shown in Fig. 1. The semi-circular canals are interconnected with the main sacs within the human ear. The utricle and the saccule build the otolith organs. The theory about angular acceleration and an inertial induced flow of endolymph was described by Mach [2]. This was the first mathematical description of flow in the canals. The vestibular canal-based coordinate system could expand to the central nervous system (CNS) to represent angular head movement used by the brain to encode and determinate movement in three-dimensional space [3]. 3D rotational information are processed by the brain and directed with maximal response directions.

BPPV is the most common vestibular disorder. It occurs due to the presence of basophilic particles in the semicircular canals. These particles are displaced otoconia (calcium carbonate crystals) from the utricle and their motion through semicircular canal system is driven by gravity. BPPV usually has these primary symptoms: nausea, dizziness, vertigo and ocular nystagmus. These symptoms are divided into two categories - tonic and phasic. Tonic symptoms include maintained ocular nystagmus initiated with different orientation of the head relative to the gravity and it is called cupulolithiasis [4]. The second category of symptoms - phasic symptoms occur with a delayed beginning and weaken over time. It is called canalithiasis, and it is typically attributed to the 
movement of free-floating particles in the lumen of the

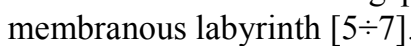

In the case of canalithiasis, a non-surgical canalith repositioning procedures (CRP) is applied. It consists of a series of timed head reorientations conceived for relocation of the particles under gravity from the horizontal canal (HC) lumen to the utricular vestibule

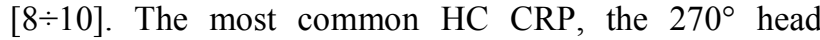
rotation [11], has been shown to relieve the symptoms of canalithiasis HC-BPPV in approximately $73 \%$ of patients [12].

The most common diagnostic procedure for BPPV is the Dix-Hallpike head maneuver [13]. This therapeutic procedure implies tilting of the head backwards by 120 degrees with the plane of rotation placed with both the plane of the posterior SCC and the direction of gravity.

The cupula makes elastic feedback which results in post-rotatory cupula displacement triggering the spinning feeling. Free-floating particulate matter from otolithic material was found by Parnes \& McClure [14], in the posterior canal of living BPPV patients. Otoconia from canaliths detach from the utricular macula and come to the open-end of the SCC. It is well known that most BPPV patients are cured by head maneuvers $[15 \div 18]$. These head maneuvers imply several reorientations of the patient's head whereby the main point is to move canaliths out of the narrow SCC into the larger utricle.

There are many one-canal approach models but they do not account for fluid coupling between canals and they cannot depict the role of the SCC geometry as a response to complex 3D head movements. Therefore, it is

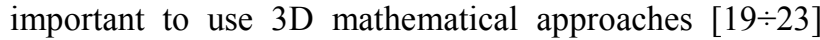
which make predictions of the temporal response dynamics and directional sensitivity of the human semicircular canals. House \& Honrubia [24] extended the force of the over-damped pendulum equation for a onedimension canal model to account for the transcupular pressure induced by the particles. Drawback of their model is in exclusion of the particle-particle and the particle-wall interaction. Rajguru et al. [25] analysed more sophisticated equations proposed by Rabbitt et al. [26] for a three-canal model. The Stokes drag description was used by Obrist \& Hegemann [27] to couple Van Buskirk's equation [28] with the particle equation of motion. All above described models are one-dimensional, where the particle is constrained to the centerline of the canal. Here, particle velocity and the induced pressure depend only on the one-dimensinal (axial) position of the particle. A two-dimensional model was introduced by Squires et al. [29] where particles are tracked in axial and radial position. Obrist \& Hegemann [27] describe with modal analysis the cupula displacement dependence on the size and number of the particles. They investigated two new modes - the fast and the slow particle modes. All models did not account for the fluid dynamics interaction between particles, and between the particles and the wall, but model particle clusters as group of heavy particles considering the mass of the whole cluster.

In this paper 3D model for parametric SCC and with real patient geometry by full fluid-structure interaction approach for particle, wall, cupula deformation and endolypmh flow is presented. Firstly, numerical procedures for parametric and 3D SCC finite element solver with fluid-structure interaction are described. Some results for parametric one SCC and fully three SCC from real patients are given. Finally, some correlations of the numerical results with experimental measurement and conclusions are given.

\section{Methods}

\subsection{Physiological description}

The most common type of vertigo is a top-shelf vertigo or BPPV. The symptoms of BPPV appear after head angular movements. This disease leads to dizziness, imbalance and nausea. This condition can be found in the entire population and especially in elderly people. It is standardly diagnosed during and after a head maneuver while tracking eye movements. This tracking of the eyes or nystagmus compensates for angular motions so that vision can be stabilized. It is also indicator for the perceived angular velocity. Basic fluid dynamics and tracking of sedimenting particles in a SCC have been shown in Fig. 2. The sedimenting particles are moving through the SCC with the fluid motion and gravity. Dizziness appears when these particles hit the cupula and make wrong sensation of the patient.

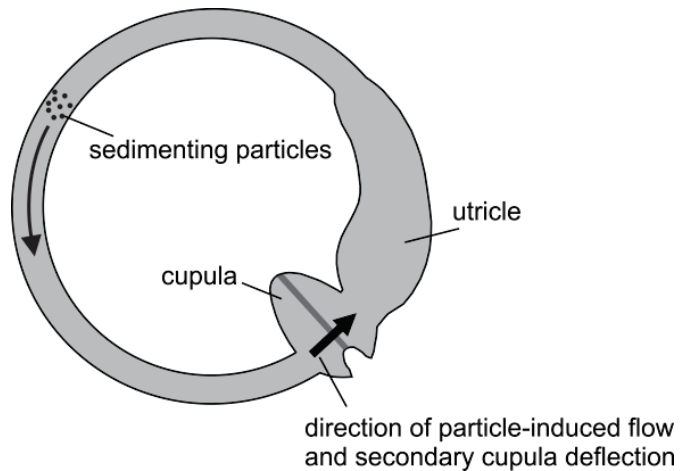

Figure 2 Basic fluid dynamics and tracking of sedimenting particles in a semicircular canal

\subsection{Numerical procedure for fluid domain}

Three-dimensional Navier-Stokes equation with continuity equation are used for fluid motion simulation. Pressure values in the calculation is eliminated with Penalty method [30]. The numerical procedure is as follows. The continuity equation is described as:

$v_{i, i}+\frac{p}{\lambda}=0$

where $\lambda$ is a selected large number, the penalty parameter. The pressure $p$ in Eq. (1) can be replaced into the NavierStokes equations:

$\rho\left(\frac{\partial v_{i}}{\partial t}+\partial v_{i, k} v_{k}\right)-\lambda v_{j, i j}-\mu v_{i, k k}-f_{i}^{V}=0$,

then the finite element equation of balance becomes:

$\boldsymbol{M} \dot{\boldsymbol{V}}+\left(\boldsymbol{K}_{v v}+\boldsymbol{K}_{v v}^{k}\right) \boldsymbol{V}=\boldsymbol{F}_{v}+\boldsymbol{F}_{\lambda}$ 
where

$$
\begin{aligned}
& {\left[K_{K, J}^{\lambda}\right]_{i, k}=\lambda \int_{V} N_{K, i} N_{J, k} \mathrm{~d} V,} \\
& \left(\boldsymbol{F}_{\lambda}\right)_{K, i}=\lambda \int_{S} N_{K} v_{j, j} n_{i} \mathrm{~d} S .
\end{aligned}
$$

\subsection{A numerical procedure for solid-fluid interaction}

In everyday engineering application, fluid acts on solid which produces surface loads and deformation of solid materials. Morevoer, deformation of solid has influence on the fluid flow. Two different approaches for finite element modelling of solid-fluid interaction problems are strong and loose coupling method. Strong coupling method uses solid and fluid domains as one mechanical system. The second approach for loose coupling considers fluid and solid separately, where the parameters from one domain have influence on the solution for the other domain. These solutions are successively transferred. In loose coupling method, balance equations systems are formed separately for the two domains which assume less computational difficulties. In this regard, loose coupling method is better considering that it is more practical. With loose coupling method, the successive solutions are calculated for the solid and fluid domains. A graphical scheme of the loose coupling algorithm for the fluid-solid interaction problem has been shown in Fig. 3 [30].

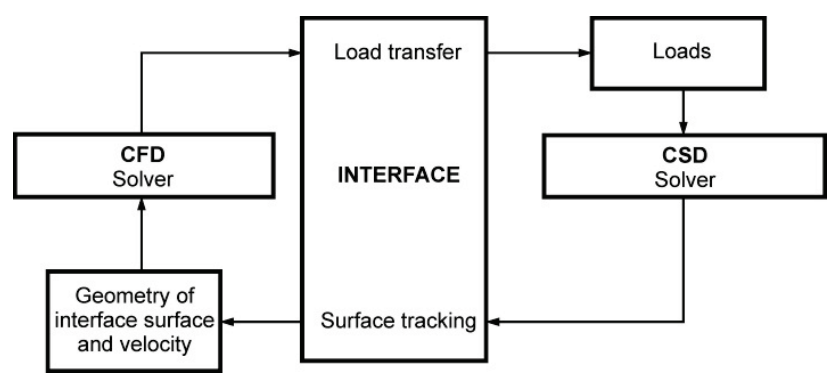

Figure 3 Fluid-solid interaction algorithm. Transfer of data between the CSD (computational solid dynamics) and CFD (computational fluid dynamics) solvers through the interface (load transfer and surface tracking)

We implemented fluid-structure interaction for cupula deformation and endolymph flow. Cupula was considered an elastic 3D membrane modelled with brick finite element and endolymph domain as 3D 8-node finite elements.

\subsection{ALE (Arbitrary Lagrangian Eulerian) formulation}

ALE (Arbitrary Lagrangian Eulerian) formulation is implemented for mesh motion. We applied incremental analysis where linearization is used with respect to time, using the known values at the start of a time step $n$. The approximation for quantity $F$ is the following:

$\left.{ }^{n+1} F\right|_{n_{\xi}}=\left.{ }^{n} F\right|_{n_{\xi}}+F^{*} \Delta t$
This approximation has been used to the left (LHS) and right $(R H S)$ hand side, where

${ }^{n}(L H S)+(K H S)^{*} \Delta t={ }^{n+1}(R H S)$

The following relations are used for calculating the meshreferential time derivatives:

$\left(\frac{\partial F}{\partial x_{i}}\right)^{*}=\frac{\partial F^{*}}{\partial x_{i}}-\left(\frac{\partial v_{k}^{m}}{\partial x_{i}}\right) \frac{\partial F}{\partial x_{k}}$

and

$(\mathrm{d} V)^{*}=\frac{\partial v_{k}^{m}}{\partial x_{k}} \mathrm{~d} V$

With these linearizations, the governing equations of fluid motion can be written as [30]:

${ }^{n} \boldsymbol{M}_{(1)} \boldsymbol{V}^{*}+{ }^{n} \boldsymbol{K}_{(1) v v} \Delta \boldsymbol{V}+{ }^{n} \boldsymbol{K}_{v p} \Delta \boldsymbol{P}={ }^{n+1} \boldsymbol{F}_{(1)}-{ }^{n} \boldsymbol{F}_{(1)}$

and

${ }^{n} \boldsymbol{M}_{(2)} \boldsymbol{V}^{*}+{ }^{n} \boldsymbol{K}_{(2) v v} \Delta \boldsymbol{V}={ }^{n+1} \boldsymbol{F}_{(2)}-{ }^{n} \boldsymbol{F}_{(2)}$.

The integrals are evaluated over the known FE volumes and surfaces at start of time step. Some parts of the Eq. (10) are calculated using the last iteration values. The mesh-referential time derivatives $\boldsymbol{V}^{*}$ and $\boldsymbol{P}^{*}$ are replaced by $\boldsymbol{V}^{*}=\Delta \boldsymbol{V} / \Delta t$ and $\boldsymbol{P}^{*}=\Delta \boldsymbol{P} / \Delta t$ to obtain the incremental algebraic equations.

Above described formulation of finite element modelling is used in the cases where fluid boundaries change significantly over time. That is very important when the boundary of the fluid represents a deformable solid, for simulation of the solid-fluid interactions. The mesh motion is dependent on each individual problem and it should be specifically defined. We concluded in the previous publication that solution for the fluid flow does not depend on the finite element mesh motion [30].

\subsection{Parametric model of SCC}

The parametric model of one semi-circular canal is presented in the Fig. 4. User can prescribe different lengths and radius curvature and results for 3D one SCC may be quickly calculated.

The finite element mesh and coordinate system of three-dimensional human membranous labyrinth has been shown in Fig. 5.

The endolymph and cupula physical properties are taken from literature [20]. Patient specific 3D SCC model with 8 node brick mesh has been presented in Fig. 6 . 


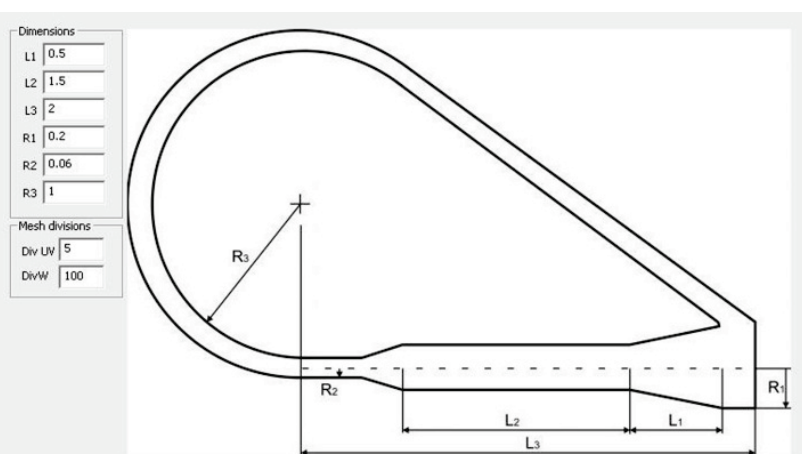

Figure 4 Parametric model of one semicircular canal

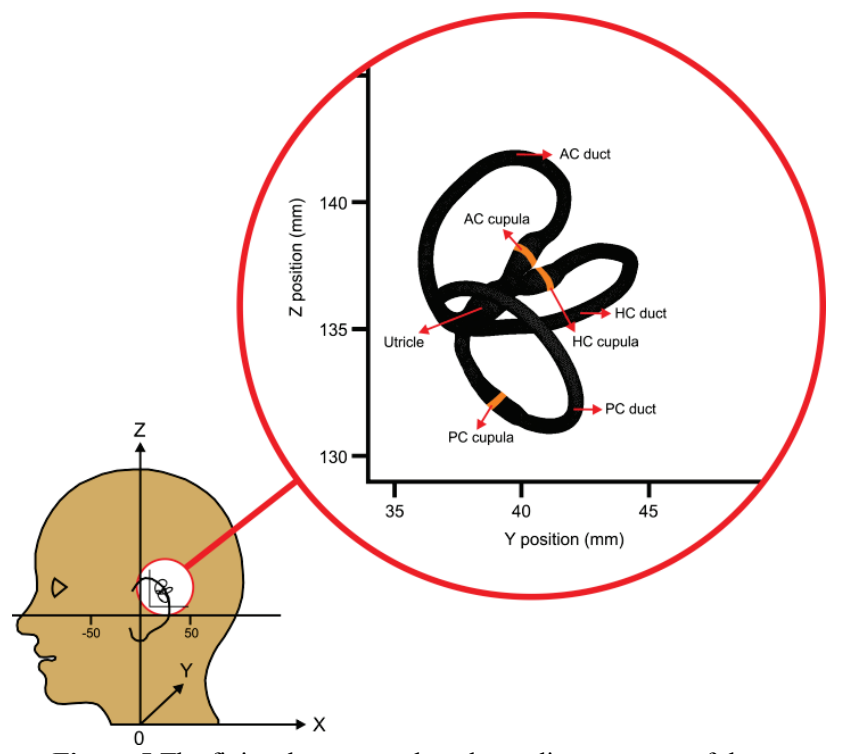

Figure 5 The finite element mesh and coordinate system of threedimensional human membranous labyrinth

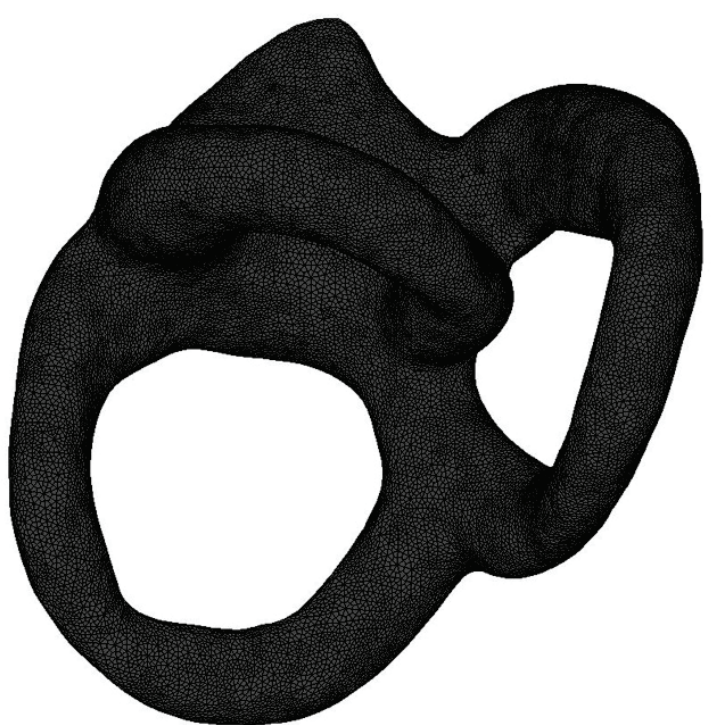

Figure 6 Patient specific 3D SCC model with 8-node brick mesh

\subsection{Particle tracking algorithm}

Otoconia particle was modelled as single particle with corresponding volume which occupied one or more 3D 8-node finite elements. In this way there is also hydrodynamic influence from particle on fluid as fluid on particle which is fully coupled model.

In the particle tracking algorithm, it is necessary to determine which finite element contains a specified point.
The coordinates of a point are divided into their integer and fractional parts: $\vec{x}=(x, y, z)=[i, j, k]+(\alpha, \beta, \gamma)$,

where $i, j, k$ are integers and $\alpha, \beta, \gamma \in[0,1]$. $[i, j, k]$ are referred to as indices and $(\alpha, \beta, \gamma)$ are referred to as offsets in many papers. Point location is as simple as truncating the coordinates to their integer parts. The integer parts determine the finite element where the point is located. The offsets have been used to make a weighted interpolation.

Current position of the particle velocity is required to move the particle in advance. Procedure for obtaining the value of the velocity field at points other than the grid nodes, uses interpolated value of the velocities at the nodes of the finite element that contains the point. In the three-dimensional finite element trilinear interpolation can be used. This interpolation is simple and fast. If $\vec{x}$ is in grid cell $[i, j, k]$ and has the partial offsets, then $(\alpha, \beta, \gamma)$ are:

$\vec{U}(i+\alpha, j+\beta, k+\gamma)=$

$=\left[\left(\vec{U}_{i, j, k} \cdot(1-\alpha)+\vec{U}_{i+1, j, k} \cdot \alpha\right) \cdot(1-\beta)+\right.$

$\left.+\left(\vec{U}_{i, j+1, k} \cdot(1-\alpha)+\vec{U}_{i+1, j+1, k} \cdot \alpha\right) \cdot \beta\right] \cdot(1-\gamma)+$

$+\left[\left(\vec{U}_{i, j, k+1} \cdot(1-\alpha)+\vec{U}_{i+1, j, k+1} \cdot \alpha\right) \cdot(1-\beta)+\right.$

$\left.+\left(\vec{U}_{i, j+1, k+1} \cdot(1-\alpha)+\vec{U}_{i+1, j+1, k+1} \cdot \alpha\right) \cdot \beta\right] \cdot \gamma$.

Where $\vec{U}_{i, j, k}$ is the velocity at the mesh point $(i, j$, $k)$. The trilinear interpolation assumes that the velocity changes in a linear manner across the edges of the finite element. There may be low accuracy with coarse or deformed mesh.

The integration methods that can be uses are the firstorder Euler scheme as well as the fourth-order RungeKutta. Integrating Eq. (11), the positions of the particle can be computed. Hence, the particle position after time $\Delta t$ is as follows:

$\vec{x}(t+\Delta t)=\vec{x}(t)+\int_{t}^{t+\Delta t} \vec{U}(\vec{x}(t), t) \mathrm{d} t$.

If the velocity is constant in the interval $[t, t+\Delta t]$, then the solution to the above equation is:

$\vec{x}(t+\Delta t)=\vec{x}(t)+\vec{U}(\vec{x}(t), t) \Delta t$

This is a quite simple integration method called the Euler formula. The first two terms of a Taylor series are actually placed on the right side. The Runge-Kutta method is fourth-order which is more accurate integration scheme. This method is the following:

Let $t=t_{1}, k=0$ and $\vec{x}_{k}$ be the current position of the particle. Then for $t<t_{n}$ and $G$ on, let

$$
\begin{aligned}
& a=\vec{U}\left(\vec{x}_{k}, t\right) \Delta t, \quad b=\vec{U}\left(\vec{x}_{k}+a / 2\right) \Delta t, \\
& c=\vec{U}\left(\vec{x}_{k}+b / 2\right) \Delta t, \quad d=\vec{U}\left(\vec{x}_{k}+c\right) \Delta t, \\
& \vec{x}_{k+1}=\vec{x}_{k}+(a+2 b+2 c+d) / 6, \\
& t=t+\Delta t, \quad k=k+1
\end{aligned}
$$


This process is repeated until $t<t_{n}$.

\section{Results}

Force distribution for the parametric model of one semicircular canal is presented in the Fig. 7. Different lengths and radius curvature can be prescribed and results for 3D one SCC may be quickly calculated. This simple model can be used for a detailed three-dimensional study of fluid flow behaviour and understanding mechanism of different disease as BPPV. User can prescribe different head motions and see the results for the endolymph fluid flow, shear stress, deformation, drag force on the wall and fluid velocity.

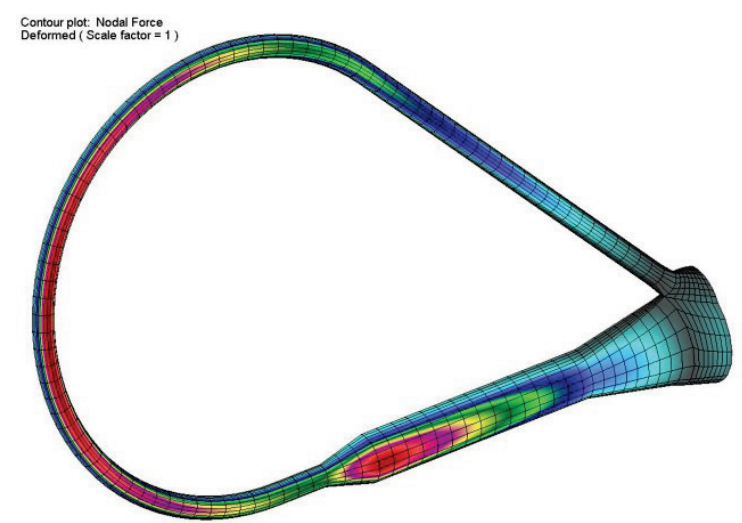

Figure 7 Total force from fluid which reacted to the wall of the semicircular canal

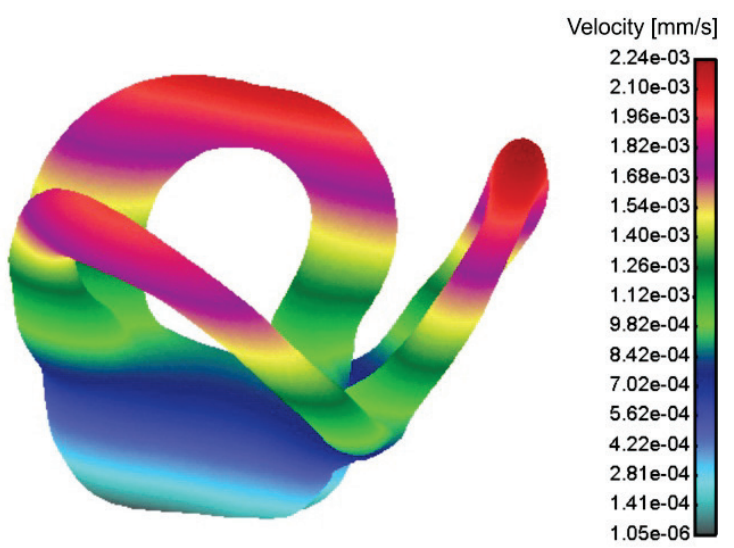

Figure 8 Fluid velocity distribution of the real patient-specific geometry of three SCC for prescribed head motion

Fluid velocity distribution of three SCC for real patient-specific geometry for prescribed head motion is presented in Fig. 8. A 3D reconstruction was done with our software platform from original DICOM images. A user can prescribe a different head motion and see the response for all three SCC with numerical results such as shear stress distribution, cupula deformation, drag force on the wall and velocity.

Head motion with corresponding canalith repositioning procedures moves the endolymph in $\mathrm{HC}$ duct. There is also velocity in the two vertical SSC. HC cupula deformation is induced by flow due to fluid forces acting on the cupula wall. Shear stress distribution is shown in Fig. 9. It can be observed that more dominant maximum shear stress distribution is accumulated on the cupula walls.

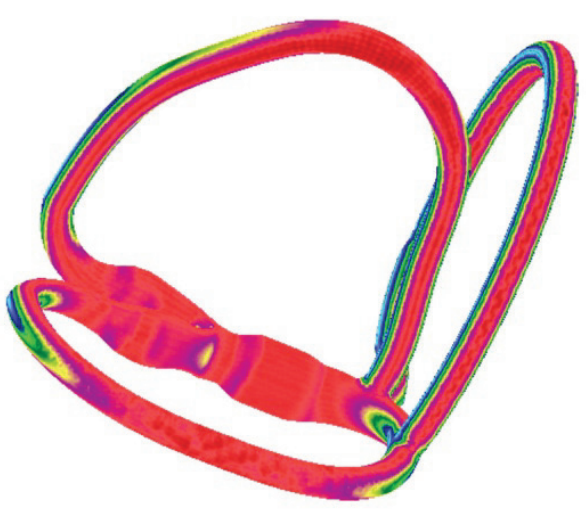

Shear stress $[\mathrm{Pa}]$

$4.03 \mathrm{e}-08$

$3.78 \mathrm{e}-08$

$3.53 \mathrm{e}-08$

$3.27 \mathrm{e}-08$

$3.02 \mathrm{e}-08$

$2.77 \mathrm{e}-08$

$2.52 \mathrm{e}-08$

$2.27 \mathrm{e}-08$

$2.02 \mathrm{e}-08$

$1.76 \mathrm{e}-08$

$1.51 \mathrm{e}-08$

$1.26 \mathrm{e}-08$

$1.01 \mathrm{e}-08$

$7.56 \mathrm{e}-09$

$5.04 \mathrm{e}-09$

$2.52 \mathrm{e}-09$

$0.00 e+00$ L

Figure 9 Shear stress distribution

Force [N]

$1.00 \mathrm{e}-06$
$9.37 \mathrm{e}-07$

$8.75 \mathrm{e}-07$

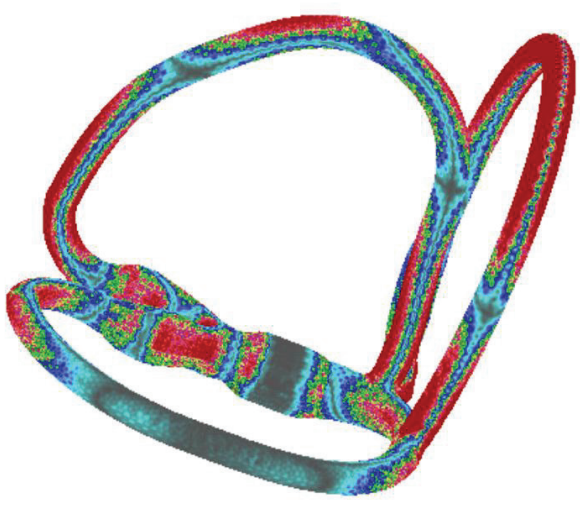

8.12e-07

$7.50 \mathrm{e}-07$

$6.87 \mathrm{e}-07$

$6.25 \mathrm{e}-07$

$5.63 \mathrm{e}-07$

$5.00 \mathrm{e}-07$

4.37e-07

$3.75 \mathrm{e}-07$

3.12e-07

$2.50 \mathrm{e}-07$

$1.88 \mathrm{e}-07$

$1.25 \mathrm{e}-07$

$6.25 \mathrm{e}-08$

$0.00 \mathrm{e}+00$

Figure 10 Forces distribution acting from endolymph side

The forces acting from endolymph flow are presented in Fig. 10.

$\mathrm{HC}$ cupula received less forces from the fluid side than from the other parts of SSC walls, but HC cupula part is responsible for sensation and deflection of the cells and transport of information to the brain.

Comparison with numerical model of one SCC with cupula deformation and three sedimenting particles which are moved inside the fluid domain and eye tracking motion is done during the Dix-Hallpike test [13] for BPPV (Fig. 11). The test is performed when a person changes the position from sitting to a supine position, with the head turned $50^{\circ}$ to one side and extended about $25^{\circ}$ backward. Experts usually observe the eyes for about 30 seconds. If nystagmus does not occur, the person is asked to return to a sitting position. A delay takes about 30 seconds, and then the other side is tested.
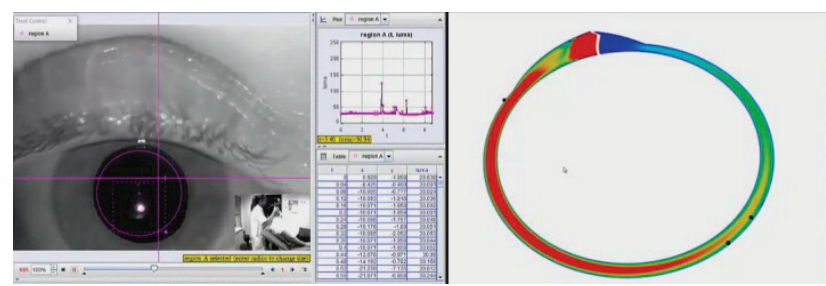

Figure 11 Eye tracking analysis and simulation of the particles and cupula deformation 
Computational model with fluid-solid interaction which takes into account endolymph fluid and cupula membrane deformation was investigated. Otoconia particle motion is described with particle tracking algorithm while particle-fluid domain is simulated with fluid-solid interaction.

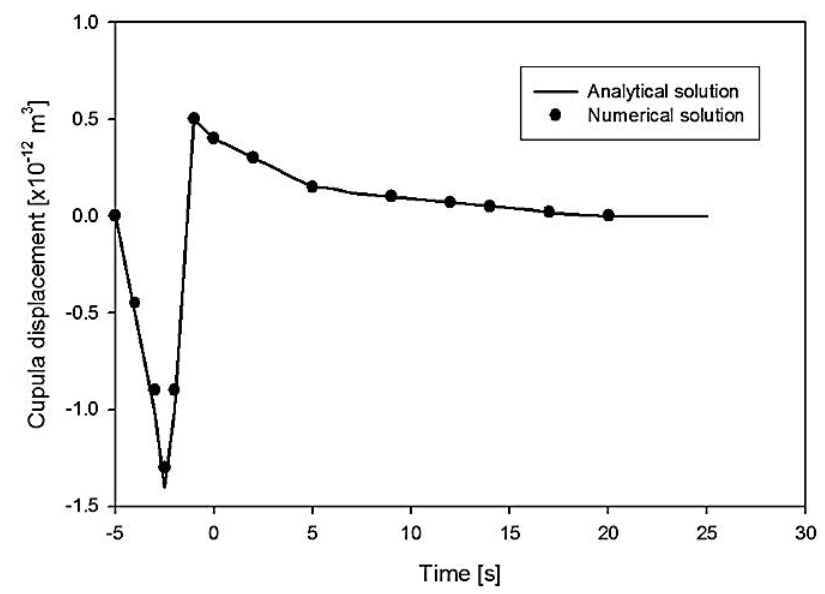

Figure 12 Analytical and numerical solution for cupula deformation for head manoeuvre from 0 to $120^{\circ}$

Analytical [27] and computational solution for cupula deformation for head manoeuvre from 0 to $120^{\circ}$ has been shown in Fig. 12.

\section{Discussion}

In this study a full 3D mathematical model of the semi-circular canal is investigated. Particularly it is concentrated to BPPV with both cupulolithiasis and canalithiasis, with sedimenting floating particle within the lumen of the membranous labyrinth. Standard CRP for BPPV with parametric one and full three SCC are investigated. There are several $3 \mathrm{D}$ mathematical models of SCC $[20 \div 23]$, but all of them did not take into consideration full 3D Navier-Stokes equations, fluidstructure interaction and for particle motion full 3D tracking algorithm. This approach gives more realistic description of the SCC, fluid motion, otoconia interaction with wall, fluid and cupula and cupula elastic deformation. Otoconia cluster is used and there is no limit in the otoconia particles number and size. Inside the fluid domain, the vortices can be simulated inside the untricle and ampula which is not the case in the present literature models. In this way, cupula deformation in $3 \mathrm{D}$ can be very complex, not just integral from the flow domain as it is used in the literature now $[21 \div 23]$. It is also easy to implement nonlinear behaviour of cupula deformation when experimental data for material model description will be available. Some authors determined the behaviour of thin membrane deflection in function of radius with a constant pressure value. In two dimension simulation, approximately 25 otoconia, or $0: 2 \mathrm{mg}$; are required to account for the peak nystagmus [29].

This calculation is CPU very demand calculation but with new generation of GPU and parallel computing algorithm it is very close to approach to do this kind of simulation almost in real time. Different simulation results for one parametric SCC, patient specific three SCC are presented. Finally, some comparison with numerical results and measurements using video tracking head and eye movement system are described.

The results presented in this paper could be used for everyday clinical practice for educational purposes and probably in terms of position of otoconia particles and BPPV diagnostic and therapy.

\section{Conclusions}

The parametric and a full 3D mathematical model of the semi-circular canal with full fluid-solid interaction of otoconia particle, endolymph fluid flow and cupula deformation is investigated. The basic explanation of physiological background of vestibular system is firstly described, then finite element numerical algorithms for fluid and fluid-structure interaction are given. Different simulation results for one parametric SCC, patient specific three SCC has been shown. Simulation of several head positions with this model may provide exact position of the fluid and all fluid dynamics parameters, shear stress, forces from fluid, cupula deflection. This may help medical doctors for better diagnostic procedures and therapy of balance disorder disease.

\section{Acknowledgment}

This study is financially supported by the projects: III41007 and ON174028 Ministry of Education, Science and Technological Development of Serbia and FP7 610454 EMBalance project.

\section{References}

[1] Berthoz, A. The sense of movement. Harvard University Press, 2002.

[2] Mach, E. Grundlinien der Lehre ion den Bewegungss empfindungen. Leipzig: Wilhelm Engelmann, 1875.

[3] Dickman, J. D. Spatial orientation of semicircular canals and afferent sensitivity vectors in pigeons. // Exp. Brain Res. 111, 1(1996), pp. 8-20. https://doi.org/10.1007/BF00229550

[4] Schuknecht, H. F. Positional vertigo: clinical and experimental observations. // Trans Am Acad Opthalmol Otol. 66 (1962), pp. 319-331.

[5] Epley, J. M. The canalith repositioning procedure: for treatment of benign paroxysmal positional vertigo. // Otolaryngol Head Neck Surg. 107 (1992), pp. 399-404. https://doi.org/10.1177/019459989210700310

[6] Hall, S. F.; Ruby, R. R.; McClure, J. A. The mechanics of benign paroxysmal vertigo. // J Otolaryngol. 8 (1979), pp. 151-158.

[7] Parnes, L. S.; McClure, J. A. Free-floating endolymph particles: a new operative finding during posterior semicircular canal occlusion. // Laryngoscope. 102 (1992), pp. 988-992. https://doi.org/10.1288/00005537-199209000-00006

[8] De la Meilleure, G.; Dehaene, I.; Depondt, M.; Damman, W.; Crevits, L.; Vanhooren, G. Benign paroxysmal positional vertigo of the horizontal canal. // J Neurol Neurosurg Psychiatry. 60 (1996), pp. 68-71. https://doi.org/10.1136/jnnp.60.1.68

[9] Furman, J. M.; Cass, S. P.; Briggs, B. C. Treatment of benign positional vertigo using heels-over-head rotation. // Ann Otol Rhinol Laryngol. 107 (1998), pp. 1046-1053. https://doi.org/10.1177/000348949810701209 
[10] Lempert, T.; Tiel-Wilck, K. A positional maneuver for treatment of horizontal-canal benign positional vertigo. // Laryngoscope. 106 (1996), pp. 476-478. https://doi.org/10.1097/00005537-199604000-00015

[11] Lempert, T. Horizontal benign positional vertigo. // Neurology. 44 (1994), pp. 2213-2214. https://doi.org/10.1212/WNL.44.11.2213-a

[12] Nuti, D.; Agus, G.; Barbieri, M. T.; Passali, D. The management of horizontal-canal paroxysmal positional vertigo. // Acta Otolaryngol. 118 (1998), pp. 455-460. https://doi.org/10.1080/00016489850154559

[13] Dix, M. R.; Hallpike, C. S. The pathology, symptomatology and diagnosis of certain common disorders of the vestibular system. // Proc. R. Soc. Med. 45, 6(1952), pp. 341-354. https://doi.org/10.1177/000348945206100403

[14] Parnes, L.S.; McClure, J.A. Free-floating endolymph particles: A new operative finding during posterior semicircular canal occlusion. // Laryngoscope. 102, 9(1992), pp. 988-992. https://doi.org/10.1288/00005537-199209000-00006

[15] Epley, J. The canalith repositioning procedure: for treatment of benign paroxysmal positional vertigo. // Otolaryngol. Head Neck Surg. 107, 3(1992). https://doi.org/10.1177/019459989210700310

[16] Semont, A.; Freyss, G.; Vitte, E. Curing the BPPV with a liberatory maneuver. // Otorhinolaryngol. 42 (1988).

[17] Parnes, L.; Price-Jones, R. Particle repositioning maneuver for benign paroxysmal positional vertigo. // Ann. Otol. Rhinol. Laryngol. 102, 5(1993). https://doi.org/10.1177/000348949310200501

[18] Ghanem, T. A.; Rabbitt, R. D.; Tresco, P. A. Three dimensional reconstruction of the membranous vestibular labyrinth in the toadfish. // Opsanus tau. Hear Res. 124, 12(1998), pp. 27-43.

[19] Damiano, E. R.; Rabbitt, R. D. A singular perturbation model for fluid dynamics in the vestibular semicircular canal and ampulla. // J. Fluid Mech. 307 (1996), pp. 333372. https://doi.org/10.1017/S0022112096000146

[20] Rabbitt, R. D.; Boyle, R.; Highstein, S. M. Sensory transduction of head velocity and acceleration in the toadfish horizontal semicircular canal. // J. Neurophysiol. 72, 2(1994), pp. 1041-1048.

[21] Rabbitt, R. D. Directional coding of three-dimensional movements by the vestibular semicircular canals. // Biol. Cybern. 80, 6(1999), pp. 417-431. https://doi.org/10.1007/s004220050536

[22] Rabbitt, R. D. et al. Hair-cell versus afferent adaptation in the semicircular canals. // J. Neurophysiol. 93, 1(2004), pp. 424-436. https://doi.org/10.1152/jn.00426.2004

[23] Rabbitt, R. D.; Damiano, E. R.; Grant, J. W. Biomechanics of the vestibular semicircular canals and otolith organs. In Highstein, S. M. A. Popper, \& R. Fay (eds. The Vestibular System. Springer-Verlag New York: pp. 153-201, 2003.

[24] House, M. G.; Honrubia, V. Theoretical models for the mechanisms of benign paroxysmal positional vertigo. // Audiol. Neurootol. 8 (2003), pp. 91-99. https://doi.org/10.1159/000068998

[25] Rajguru, S. M.; Ifediba, M. A.; Rabbitt, R. D. Three dimensional biomechanical model of benign paroxysmal positional vertigo. // Ann. Biomed. Eng. 32 (2004), pp. 831846. https://doi.org/10.1023/B:ABME.0000030259.41143.30

[26] Rabbitt, R. D.; Damiano, E. R.; Grant, J. W. Biomechanics of the semicircular canals and otolith organs. In The vestibular system (ed. S. M. Highstein, R. Fay \& A. N. Popper), Springer Hand-book of Auditory Research, 19, pp. 153-201. Springer New York, 2004. https://doi.org/10.1007/0-387-21567-0_4

[27] Obrist, D.; Hegemann, S. Fluid-particle dynamics in canalithiasis. // J. Roy. Soc. Interface. 5, 27(2008), pp. 1215-1229. https://doi.org/10.1098/rsif.2008.0047
[28] Van Buskirk, W. C.; Watts, R. G.; Liu, Y. K. The fluid mechanics of the semicircular canals. // J. Fluid Mech. 78, 1(1976), pp. 87-98. https://doi.org/10.1017/S0022112076002346

[29] Squires, T. M.; Weidman, M. S.; Hain, T. C.; Stone, H. A. A mathematical model for top-shelf vertigo: the role of sedimenting otoconia in BPPV. // J. Biomech. 37, 8(2004), pp. 1137-1146. https://doi.org/10.1016/j.jbiomech.2003.12.014

[30] Filipovic, N.; Mijailovic, S.; Tsuda, A.; Kojic, M. An Implicit Algorithm within the Arbitrary LagrangianEulerian Formulation for Solving Incompressible Fluid Flow with Large Boundary Motions. // Comp. Meth. Appl. Mech. Engrg. 195 (2006), pp. 6347-6361. https://doi.org/10.1016/j.cma.2005.12.009

\section{Authors' addresses}

Nebojsa Zdravkovic, PhD, associate professor Faculty of Medical Science, University of Kragujevac Svetozara Markovica 69, 34000 Kragujevac, Serbia nzdravkovic@medf.kg.ac.rs

\section{Zarko Milosevic, PhD student}

Faculty of Engineering, University of Kragujevac Sestre Janjica 6, 34000 Kragujevac, Serbia BioIRC Research and Development Center for Bioengineering Prvoslava Stojanovica 6, 34000 Kragujevac, Serbia zarko@kg.ac.rs

\section{Igor Saveljic, PhD student}

Faculty of Engineering, University of Kragujevac Sestre Janjica 6, 34000 Kragujevac, Serbia BioIRC Research and Development Center for Bioengineering Prvoslava Stojanovica 6, 34000 Kragujevac, Serbia isaveljic@kg.ac.rs

\section{Dalibor Nikolic, PhD student}

Faculty of Engineering, University of Kragujevac Sestre Janjica 6, 34000 Kragujevac, Serbia BioIRC Research and Development Center for Bioengineering Prvoslava Stojanovica 6, 34000 Kragujevac, Serbia markovac85@kg.ac.rs

\section{Vladimir Miloradovic, assistant professor}

Faculty of Medical Science, University of Kragujevac Svetozara Markovica 69, 34000 Kragujevac, Serbia vanja.miloradovic@gmail.com

\section{Nenad Filipovic, PhD, professor}

Faculty of Engineering, University of Kragujevac Sestre Janjica 6, 34000 Kragujevac, Serbia BioIRC Research and Development Center for Bioengineering Prvoslava Stojanovica 6, 34000 Kragujevac, Serbia fica@kg.ac.rs 